\title{
Backstepping Sliding Mode Control for Inverted Pendulum System with Disturbance and Parameter Uncertainty
}

\author{
Alfian Ma'arif ${ }^{1 *}$, Marco Antonio Márquez Vera ${ }^{2}$, Magdi Sadek Mahmoud ${ }^{3}$, Samir Ladaci ${ }^{4}$, Abdullah Çakan ${ }^{5}$, Jonattan \\ Niño Parada 6 \\ ${ }^{1}$ Universitas Ahmad Dahlan, Yogyakarta, Indonesia \\ ${ }^{2}$ Polytechnic University of Pachuca, Mexico \\ ${ }^{3}$ King Fahd University of Petroleum and Minerals, Saudi Arabia \\ ${ }^{4}$ National Polytechnic School of Constantine, Algeria \\ ${ }^{5}$ Konya Technical University, Turkey \\ ${ }^{6}$ Universidad de Los Llanos, Colombia \\ Email: ${ }^{1}$ alfianmaarif@ee.uad.ac.id \\ *Corresponding Author
}

\begin{abstract}
The inverted pendulum system is highly popular in control system applications and has the characteristics of unstable, nonlinear, and fast dynamics. A nonlinear controller is needed to control a system with these characteristics. In addition, there are disturbances and parameter uncertainty issues to be solved in the inverted pendulum system. Therefore, this study uses a nonlinear controller, which is the backstepping sliding mode control. The controller is robust to parameter uncertainty and disturbances so that it is suitable for controlling an inverted pendulum system. Based on testing with step and sine reference signals without interference, the controller can stabilize the system well and has a fast response. In testing with disturbances and mass uncertainty, the backstepping sliding mode controller is robust against these changes and able to make the system reach the reference value. Compared with sliding mode control, backstepping sliding mode control has a better and more robust response to disturbances and parameter uncertainty.
\end{abstract}

Keywords-Inverted Pendulum; Backstepping; Sliding Mode Control; Nonlinear; Disturbance; Uncertainty

\section{INTRODUCTION}

Inverted pendulum system is commonly used and highly popular in control systems [1]-[3]. An inverted pendulum system can be illustrated in Fig. 1. A pendulum stick on a movable cart can move aside freely [4]. The pendulum moves according to the movement of the cart. Therefore, in order to make the pendulum stay upward steadily, the velocity of the cart needs to be controlled.

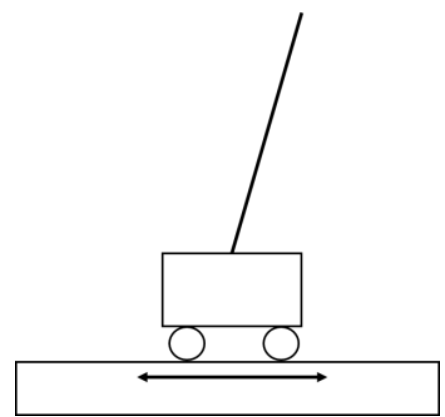

Fig. 1. Inverted Pendulum System
An inverted pendulum has characteristics as nonlinear [5], unstable [6], under-actuated system [7][8], multivariable system [9], and fast dynamic system [10]. The pendulum stick might fall easily even without the cart moving [11]. It makes the system characteristics as nonlinear and unstable. Balancing the pendulum stick requires a great and fast force. Otherwise, the stick will fall immediately. This makes an inverted pendulum system have a fast dynamic response.

The goal of the control system is to balance an inverted pendulum system by giving a control signal (force) to a cart that has been installed with a pendulum system [12][13]. Some examples of inverted pendulum system applications are: balancing system in a rocket system when the rocket takes off [14], Missile Launcher [15][16], Segway [17], balancing robots [18]-[20], humanoid robot [21]-[23], etc [24].

Some researches about inverted pendulum have been done by many. Some researchers used Proportional Integral Derivative Control (PID) [25]-[27], Fractional Oder PID [28] and some others used state feedback control with pole placement or Linear Quadratic Regulator (LQR) [29]-[33]. Linear controllers such as PID, FOPID and state feedback can control an inverted pendulum system with a linearization in its nonlinear model. However, a linearized model is just an approximation near the equilibrium with narrow angles; it cannot fully represent the dynamics of the system. Hence, a linear controller is not suitable to be used in an inverted pendulum system.

Other researchers applied fuzzy control in an inverted pendulum system [34]-[38]. According to their results, the fuzzy control can control a nonlinear inverted pendulum system, better than linear controllers. However, fuzzy logic controllers are not suitable to be used by beginners for slowprocessing systems. Additional information is needed to design a proper fuzzy controller; for example, more knowledge of the system's behavior and previous experimental data from another controller. This information will be used to design fuzzy rules that cannot be done 
arbitrarily. Furthermore, fuzzy controllers use heavy computations. Many processes need to be executed: fuzzification, defuzzification, and if-then rules. This requires a fast-processing system to achieve good performance of the system.

Other than the nonlinear characteristic of the system, the inverted pendulum also has other issues to be solved: parameter uncertainty [39][40] and disturbance [41]. Parameter uncertainty is found when the pendulum has a changing mass [42], and disturbance is often found in the real system in the form of external force, friction, or noise. Some examples of disturbance are friction force and inertia of the system. Hence, a suitable controller for an inverted pendulum system should also be robust to parameter uncertainty and disturbances.

Some variations of nonlinear controllers that can overcome parameter uncertainty and disturbance are backstepping [43] and sliding mode control [44]-[47]. The sliding mode control is good to solve parameter uncertainty and disturbance [48]. Meanwhile, backstepping control gives a good system response. Therefore, by combining those nonlinear controllers, the proposed controller can solve parameter uncertainty and disturbance with a good response.

The contribution of this research is to design a controller for a nonlinear inverted pendulum system. The proposed design of the controller is robust to parameter uncertainty and disturbance. Another contribution is to make a comparison between the proposed controllers with other controllers to assess a better controller.

This research paper is divided into some sections. The first section is an introduction that contains the background of the research. The next section is the method that consists of modeling an inverted pendulum system, a short explanation of backstepping and sliding mode control. This section also discusses the controller designs of sliding mode control and backstepping sliding mode control. The third section is results and discussions. Then, the last section is conclusions and future work suggestions.

\section{METHOD}

\section{A. Modeling an Inverted Pendulum}

Some force that works on an inverted pendulum system can be seen in Fig. 2. Variable $m_{c}$ and $m$ are the mass of the cart and the mass of the pendulum, respectively. Variable $l$ is the length of the pendulum stick, variable $\theta$ is angular position of oscillation, variable $x$ is the displacement of the cart, and variable $H$ is the applied force to the cart.

State variables of the system are the angular position of the oscillation and the angular velocity as represented in $x_{1}=$ $\theta$ and $x_{2}=\dot{\theta}$. The input variable of the system is the applied force $u=H$, and the output of the system is the angular position as $y=x_{1}$. According to [49], the nonlinear model of an inverted pendulum system can be written as

$$
\begin{gathered}
\dot{x}_{1}=x_{2} \\
x_{2}=f(x, t)+g(x, t) u+d(x, t)
\end{gathered}
$$

where

$$
\begin{gathered}
f(x, t)=\frac{g \sin x_{1}-\frac{m l x_{2}^{2} \cos x_{1} \sin x_{1}}{m_{c}+m}}{l\left(\frac{4}{3}-\frac{m \cos ^{2} x_{1}}{m_{c}+m}\right)} \\
g(x, t)=\frac{\frac{\cos x_{1}}{m_{c}+m}}{l\left(\frac{4}{3}-\frac{m \cos ^{2} x_{1}}{m_{c}+m}\right)}
\end{gathered}
$$

The $f(x, t)$ is a nonlinear function of the system's states and $g(x, t)$ is a nonlinear function of the system's input. Meanwhile, $d(x, t)$ is the function of parameter uncertainty and system's disturbance.

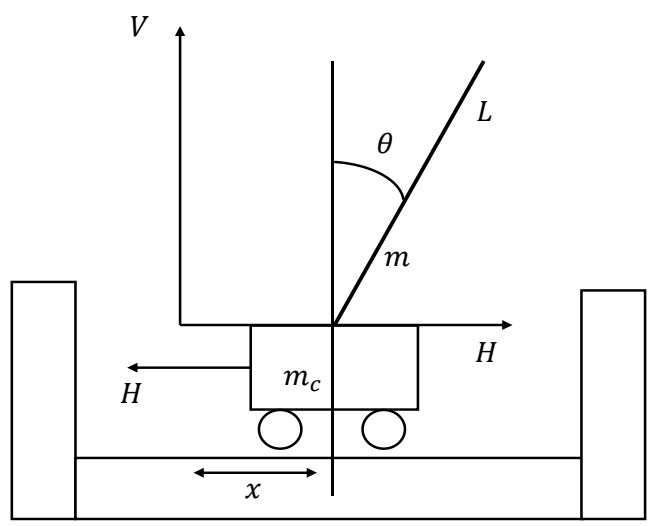

Fig. 2. Inverted Pendulum System

The nonlinearity of the inverted pendulum system is shown by $f(x, t)$ and $g(x, t)$ as in (3) and (4). Those functions contain sin and cos functions that show the system is nonlinear, differentiating the nonlinear model from a linear one.

\section{B. Backstepping Sliding Mode Control}

The block diagram of the control system is shown in Fig. 3. The reference is a referenced value that the system must achieve. The controller must be able to make the system reach the referenced value. The difference between the reference and the output (the feedback value) is an error that becomes an input to the backstepping sliding mode controller.

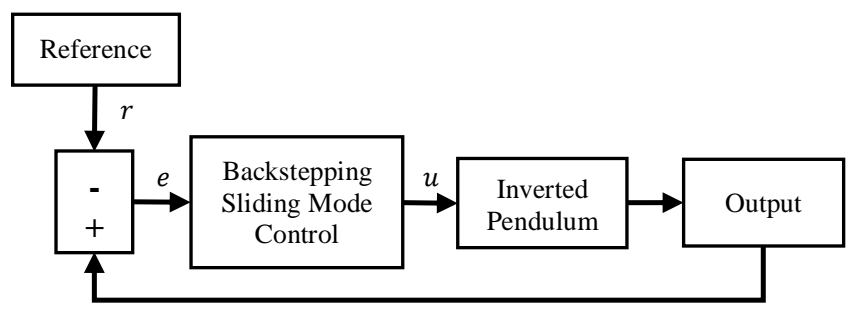

Fig. 3. Block Diagram of Augmented System

The output of the controller is the control signal that becomes an input to the inverted pendulum system. Meanwhile, the outputs of the inverted pendulum system are oscillation angle and angular velocity. These will be feedback to calculate the error. The control system will run continuously to keep the system stable.

One of nonlinear controllers is the sliding mode control. Usually, there is a difference between the actual system and 
a mathematical model that is developed for controller design. This can be called as uncertainty and can be caused by several factors. The role of the designer is to ensure the system runs well even though there is a mismatch between the model and the actual system. Based on this fact, a control method is developed to overcome the mismatch. One of the control methods is the sliding mode control. It belongs to the Variable Structure Control System (VSCS). The sliding mode control has been applied to many systems with a superiority characteristic as insensitive to parameter uncertainty and external disturbance in the sliding condition [50].

Steps to design a sliding mode controller can be written as follows. First, a reference value is defined as $r$ and the error is defined as

$$
e=r-x_{1}
$$

Then, a sliding variable is defined as

$$
s=\dot{e}+c e,
$$

with $c>0$. The first derivative of the sliding variable can be written as

$$
\begin{gathered}
\dot{s}=\ddot{e}+c \dot{e} \\
=\ddot{r}-\ddot{x}_{1}+c \dot{e} \\
=\ddot{r}-f(x, t)-g(x, t) u-d+c \dot{e}
\end{gathered}
$$

The Lyapunov function is used to design the controller, which can be written as

$$
V=\frac{1}{2} s^{2}
$$

The first derivative of the Lyapunov function is

$$
\begin{gathered}
\dot{V}=s \dot{s} \\
\dot{V}=s(\ddot{r}-f-g u-d+c \dot{e})
\end{gathered}
$$

Hence, the control signal of the sliding mode control can be written as

$$
u=\frac{1}{g}(-f(x, t)+\ddot{r}+c \dot{e}+\eta \operatorname{sgn}(s))
$$

By substituting the control signal of sliding mode control to (12), a equation can be obtained as below

$$
\begin{gathered}
\dot{V}=s(\ddot{r}-f-(-f+\ddot{r}+c \dot{e}+\eta \operatorname{sgn}(s)) \\
-d+c \dot{e}) \\
\dot{V}=s(-d-+\eta \operatorname{sgn}(s)) \\
\dot{V}=-s d-\eta|s|
\end{gathered}
$$

Meanwhile, it is known that if $\eta>D$, then the second derivative of the Lyapunov function is also negative.

$$
\dot{V}=-s d-\eta|s|<0
$$

Therefore, it can be known that the system fulfills the criteria of the Lyapunov stability.

The backstepping control is included in nonlinear control. The main idea of the backstepping control is that a complex nonlinear system can be decomposed into subsystems, and the level of the subsystem must not be greater than the whole system. Therefore, each Lyapunov and virtual control variable is designed separately; the whole system can be obtained with a backstep to design the controller fully. The backstepping method is called as back-deduce method and the desired dynamic index is fulfilled [50].

Steps to design the backstepping sliding mode controller are divided into two. The number of the step depends on the size of the system's states. Since the inverted pendulum system has 2-state model, the step design is divided into two and will be described as follows.

\section{1) Step 1}

The first step begins with defining error as

$$
e_{1}=x_{1}-r
$$

with $r$ as reference. Then, the derivative of the error is

$$
\begin{gathered}
\dot{e}_{1}=\dot{x}_{1}-\dot{r} \\
=x_{2}-\dot{r}
\end{gathered}
$$

where $\dot{r}$ is the first derivative of the reference. A Lyapunov function is used to design the controller, which can be written as

$$
V_{1}=\frac{1}{2} e_{1}^{2}
$$

The derivative of the Lyapunov function is

$$
\begin{gathered}
\dot{V}_{1}=e_{1} \dot{e}_{1} \\
=e_{1}\left(x_{2}-\dot{r}\right)
\end{gathered}
$$

To fulfill the stability of the system, the derivative of the Lyapunov function must be equal to or less than zero $\left(\dot{V}_{1} \leq\right.$ 0 ). Then, the variable $x_{2}$ is defined as

$$
x_{2}=s-c_{1} e_{1}+\dot{r}
$$

so that a new equation can be obtained as in

$$
\begin{aligned}
s= & x_{2}+c_{1} e_{1}-\dot{r} \\
& =c_{1} e_{1}-\dot{e}_{1}
\end{aligned}
$$

where $c_{1}>0$ as to fulfill Hurwitz criterion, and $s$ is defined as the sliding variable.

Then, a derivative of Lyapunov function can be achieved as

$$
\dot{V}_{1}=e_{1} s-c_{1} e_{1}^{2}
$$


2) Step 2

The second step begins with determining the second function of Lyapunov as in

$$
V_{2}=V_{1}-\frac{1}{2} s^{2}
$$

Then, the second derivative of the sliding variable (s) can be defined as

$$
\begin{gathered}
\dot{s}=\dot{x}_{2}+c_{1} e_{1}-\ddot{r} \\
=f(x, t)+g(x, t) u+d(x, t)+c_{1} e_{1}-\ddot{r}
\end{gathered}
$$

where $\ddot{r}$ is the second derivative of the reference signal.

Next, the second derivative of the Lyapunov function can be written as

$$
\begin{gathered}
\dot{V}_{2}=\dot{V}_{1}+s \dot{s} \\
=e_{1} s+c_{1} e_{1}^{2}+s(f x, t)+g(x, t) u+d(x, t) \\
+c_{1} \dot{e}_{1}-\ddot{r}
\end{gathered}
$$

To ensure the stability of the system, the derivative of the second Lyapunov function must be equal to or less than zero $\left(\dot{V}_{2} \leq 0\right)$. Therefore, the control signal can be designed as

$$
\begin{gathered}
u=\frac{1}{g(x, t)}\left(-f(x, t)-c_{2} s-e_{1}-c_{1} \dot{e}_{1}\right. \\
+\ddot{r} \eta \operatorname{sgn}(s))
\end{gathered}
$$

with $c_{2}>0, \eta>0$ and

$$
\operatorname{sgn}(s)=\left\{\begin{aligned}
1, & s>0 \\
0, & s=0 \\
-1, & s<0
\end{aligned}\right.
$$

Eventually, the derivative of the second Lyapunov function can be obtained and can be rewritten as

$$
\dot{V}_{2}=-c_{1} e_{1}^{2}-c_{2} s^{2}+s d(x, t)-\eta|s| \leq 0
$$

so that $e_{1} \rightarrow 0$ and $e_{2} \rightarrow 0$ when $t \rightarrow \infty$.

\section{RESULTS AND DISCUSSION}

Parameters of the pendulum system are as follows. The mass of the pendulum stick is $0.1 \mathrm{~kg}$, the mass of the cart is $1 \mathrm{~kg}$, the length of the pendulum is $0.5 \mathrm{~m}$, and the gravity acceleration is $9.8 \mathrm{~m} / \mathrm{s}^{2}$. The test was made using Matlab Simulink software. The simulation design is shown in Fig. 4. The reference signal, controller, and inverted pendulum blocks are made with s-function blocks. The source code of the backstepping sliding mode controller and inverted pendulum system can be seen in the Appendix section.

Some evaluations made in this research are evaluation with step signal as reference, sine wave signal as a reference, parameter uncertainty, and disturbance. A performance comparison with other control methods is also included in the discussions.

\section{A. Evaluation with Reference Signal as Variation}

The results of the augmented system with step signal and sine wave signal as reference are shown in Fig. 5 and Fig. 6.
Black-colored line represents the reference signal and bluecolored line represents the system response. $X$-axis in the graph represents time while $Y$-axis represents the system's position in meter.

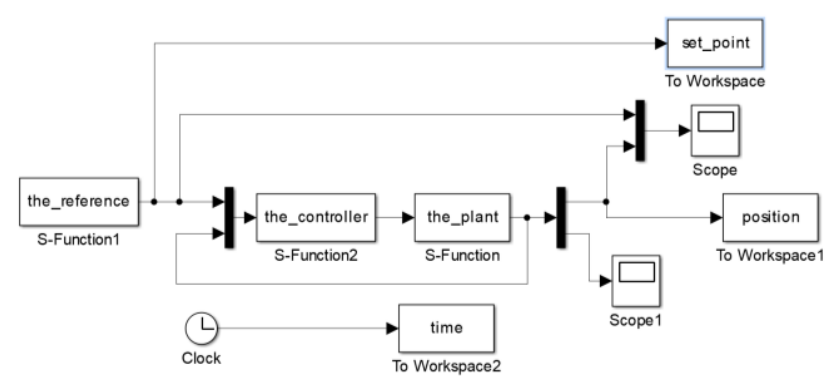

Fig. 4. Matlab Simulink Simulation Design

This evaluation aims to assess whether the controller is able to make the system reach the expected reference signal. Based on the experiment result in Fig. 5 and Fig. 6, the proposed controller can make the inverted pendulum system to follow the given reference signal. It can be seen that the blue-colored line coincides with the black-colored line. The augmented system achieved the reference value in less than 1 second. Therefore, it can be said that the controller can control the inverted pendulum system in a fast time response.

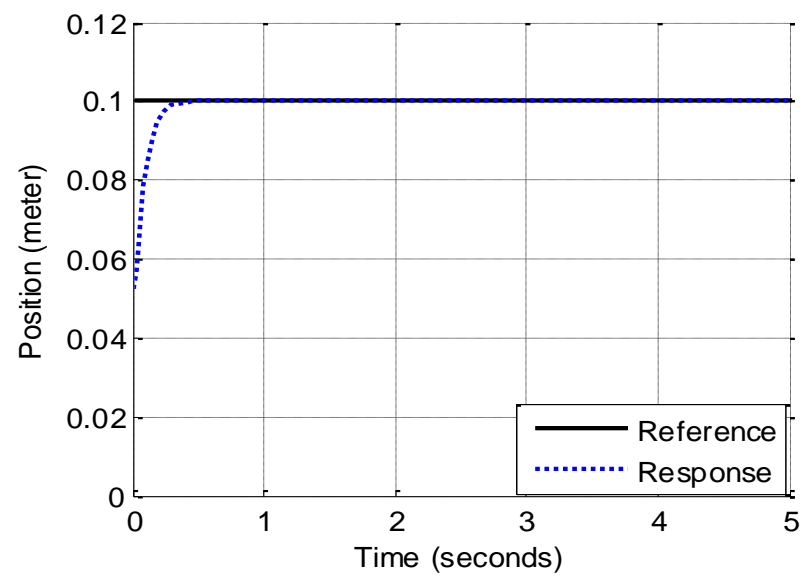

Fig. 5. System Response of Step Signal as Reference

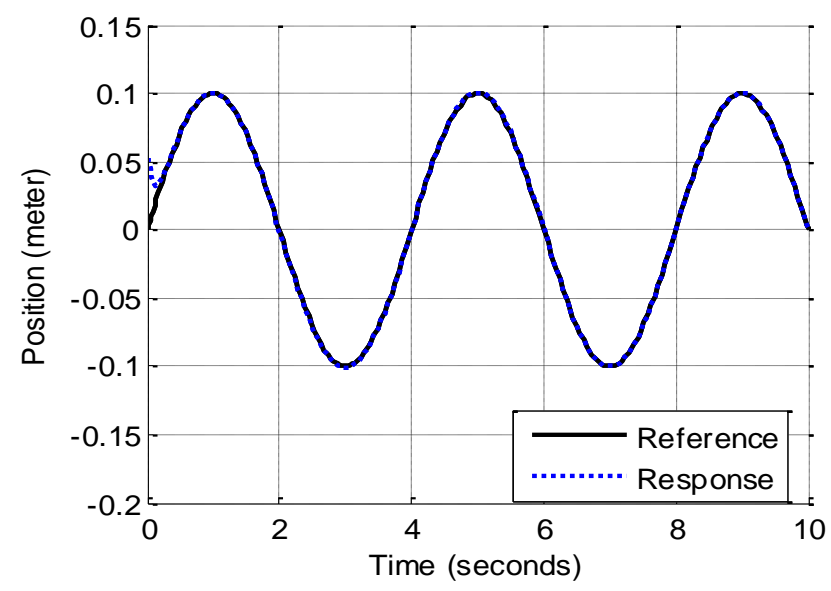

Fig. 6. System Response of Sine Wave Signal as Reference

\section{B. Evaluation with Parameter Uncertainty}

The results of the evaluation with mass uncertainty are shown in Fig. 7 and Fig. 8, with the mass changing from 
$0.1 \mathrm{~kg}$ to $0.3 \mathrm{~kg}$ and to $0.5 \mathrm{~kg}$, respectively. According to both figures, a change of the mass makes the system have steadystate error. By making the $\eta$ parameter bigger, the controller becomes more robust, and the steady-state error can be eliminated. The implementation of this idea can be seen in the result as in Fig. 9. Therefore, it can be known that the proposed controller can make the augmented system robust to parameter uncertainty.

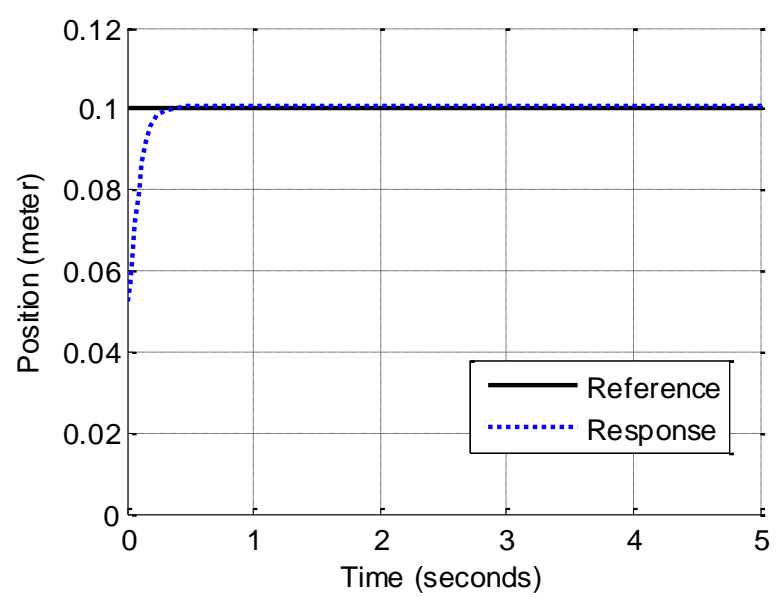

Fig. 7. System response with step as reference and mass of pendulum changing from $0.1 \mathrm{~kg}$ to $0.3 \mathrm{~kg}$

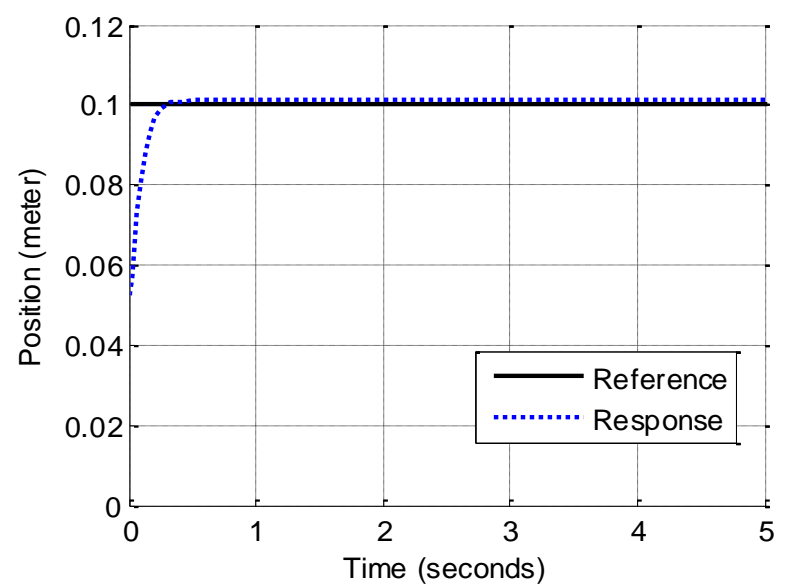

Fig. 8. System response with step as reference and mass of pendulum changing from $0.1 \mathrm{~kg}$ to $0.5 \mathrm{~kg}$

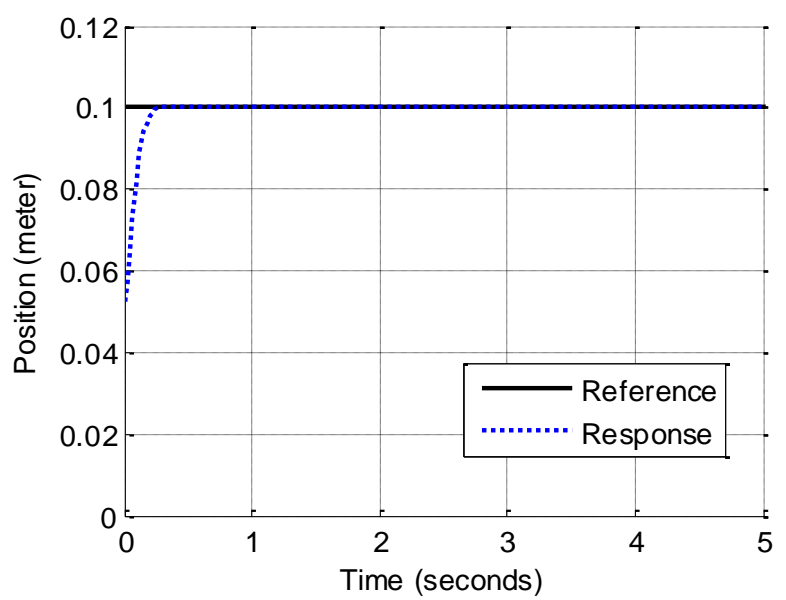

Fig. 9. System response with step as reference, mass of pendulum changing from $0.1 \mathrm{~kg}$ to $0.5 \mathrm{~kg}$, after the application of bigger $\eta$

\section{Evaluation with Disturbance}

In this subsection, an evaluation is done by adding disturbance to the system. The evaluation aims to assess the performance of the controller after the system is given with disturbance that commonly happens in the actual system. The given disturbance is defined as a sine wave that equals to $0.5 \sin 2 \pi t$. The result is shown in Fig. 10. Based on the figure, it can be seen that there are small oscillations in the system response near the reference value.

Modification of $\eta$ variable in the controller should be done to eliminate small oscillations that occurred in the system response as seen in Fig. 10. The initial value of $\eta$ is 0.03 , then it is modified to 0.05 . The result of system response after the modification can be seen in Fig. 11. According to the figure, the oscillation can be eliminated successfully.

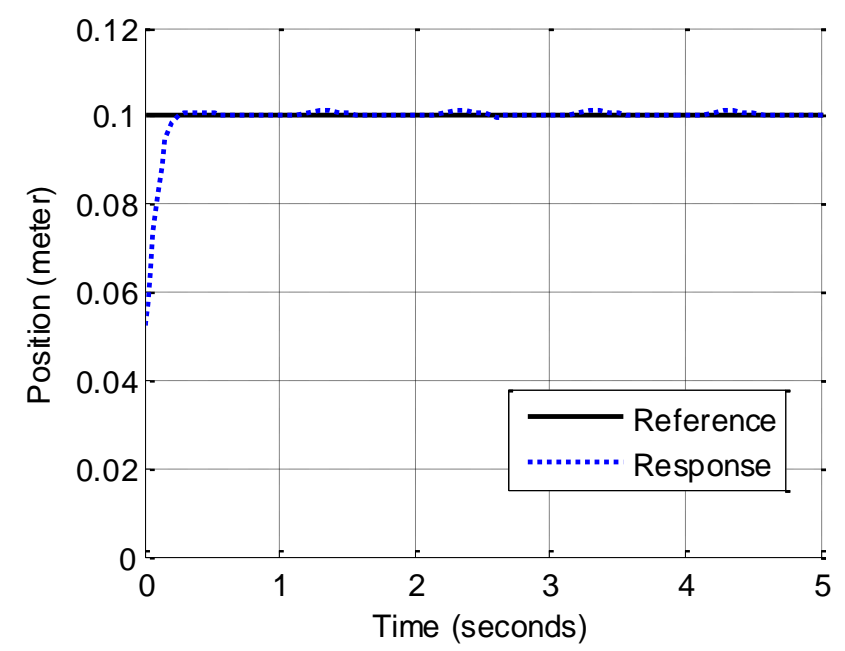

Fig. 10. System response with step as reference, mass of pendulum changing from $0.1 \mathrm{~kg}$ to $0.5 \mathrm{~kg}$, and disturbance given as $0,5 \sin 2 \pi t$

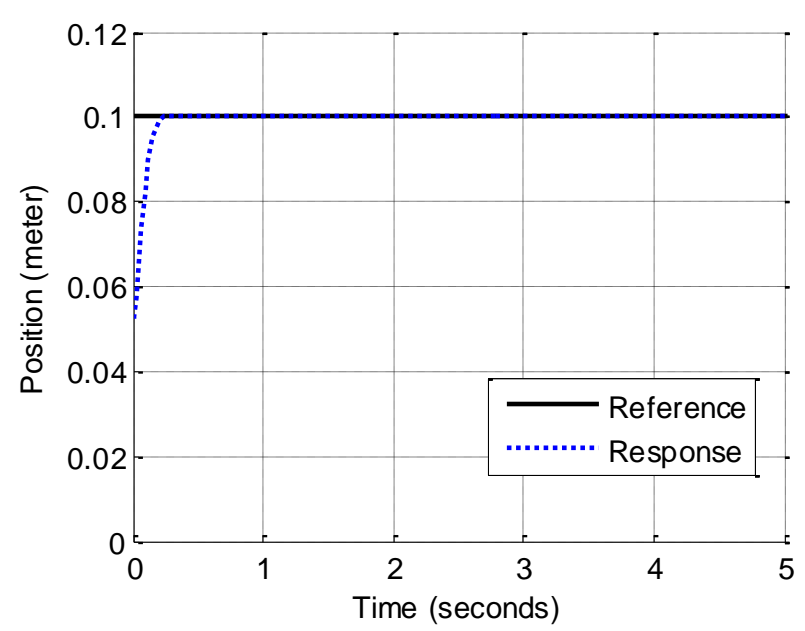

Fig. 11. System response with step as reference, mass of pendulum changing from $0.1 \mathrm{~kg}$ to $0.5 \mathrm{~kg}$, and disturbance given as $0,5 \sin 2 \pi t$, after $\eta$ is modified

\section{Performance Comparison with Other Control Methods}

In this subsection, evaluation is done to compare the performance of backstepping sliding mode controller with sliding mode controller. Performance results of both methods with step signal and sine wave as references are shown in Fig. 12 and Fig. 13, respectively. According to the results, 
backstepping sliding mode controller provides a faster system response than sliding mode controller.

The comparison of system responses with mass uncertainty and disturbance given as $\sin 2 \pi t$ can be seen in Fig. 14. Based on the figure, the backstepping sliding mode control responds more robustly than the sliding mode control. There is a big oscillation in the system response of sliding mode control, while the backstepping sliding mode control only has insignificant oscillations. These evaluation results prove that the backstepping sliding mode control has better performance and is more robust than the sliding mode control.

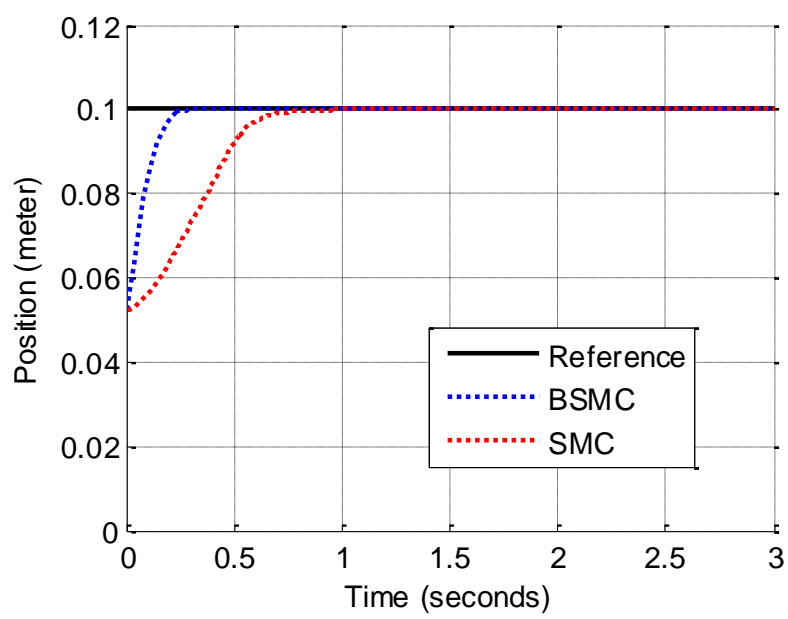

Fig. 12. System responses with step as references of Sliding Mode Controller and Backstepping Sliding Mode Controller

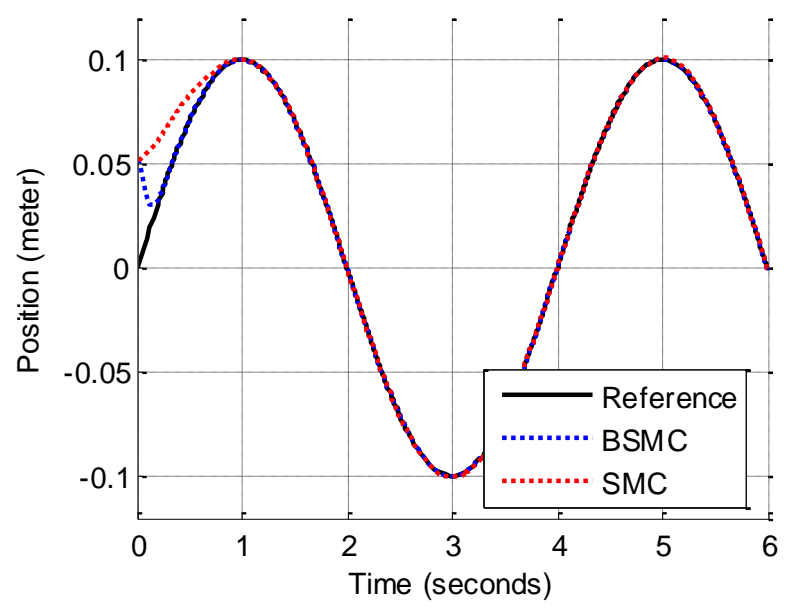

Fig. 13. Comparison of system responses with sine wave as reference between Sliding Mode Control (SMC) and Backstepping Sliding Mode Control (BSMC)

\section{CONCLUSIONS}

This research proposes a new backstepping combined with a sliding mode control method to control an inverted pendulum system with an external disturbance and parameter uncertainty. The proposed controller can make the system follow step and sine wave as reference signals based on evaluation results. In evaluating parameter uncertainty and external disturbance, the proposed controller can make the system more robust while tracking the reference signal. The system responds in a good performance with a fast response while reaching a steady state. Nevertheless, the research is still limited on simulation, so it needs implementation to the actual system for further analysis. Besides, determining the parameter of the controller to get good results still uses trial and error. Hence, choosing the parameter can use a better and more standardized method in future work.

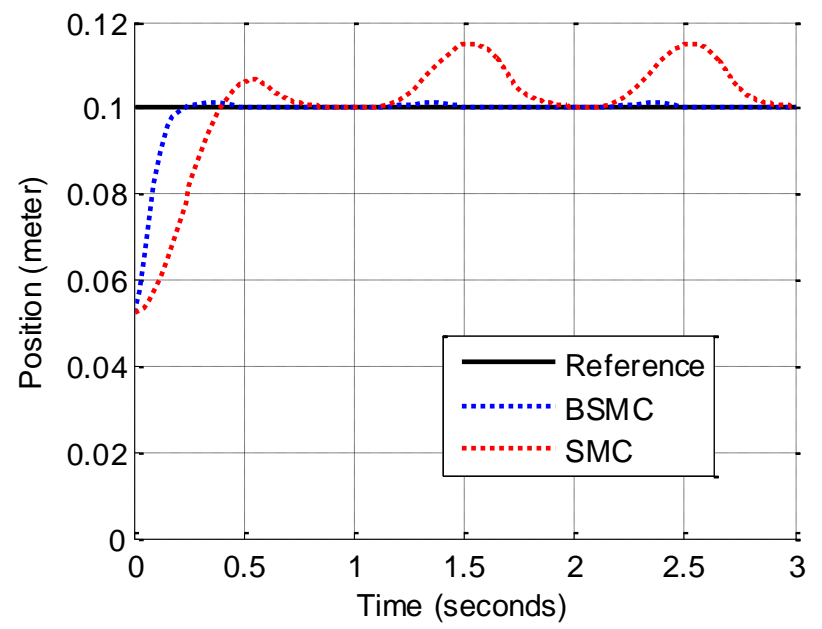

Fig. 14. Comparison of system responses between Sliding Mode Control (SMC) and Backstepping Sliding Mode Control (BSMC) with step as reference, mass of pendulum changing from $0.1 \mathrm{~kg}$ to $0.5 \mathrm{~kg}$ and disturbance given as $\sin 2 \pi t$

\section{ACKNOWLEDGMENT}

The author would like to thank to Universitas Ahmad Dahlan for the research grant and publication grant.

\section{REFERENCES}

[1] Y. Rizal, M. Wahyu, I. Noor, J. Riadi, and R. Mantala, "Design of an Adaptive Super-Twisting Control for the Cart-Pole Inverted Pendulum System," Jurnal Ilmiah Teknik Elektro Komputer dan Informatika, vol. 7, no. 1, pp. 161-174, 2021.

[2] E. Kennedy, E. King, and H. Tran, "Real-time implementation and analysis of a modified energy based controller for the swing-up of an inverted pendulum on a cart," European Journal of Control, vol. 50, pp. 176-187, 2019.

[3] J. F. S. Trentin, S. Da Silva, J. M. De Souza Ribeiro, and H. Schaub, "Inverted Pendulum Nonlinear Controllers Using Two Reaction Wheels: Design and Implementation," IEEE Access, vol. 8, pp. 7492274932, 2020

[4] X. Su, F. Xia, J. Liu, and L. Wu, "Event-triggered fuzzy control of nonlinear systems with its application to inverted pendulum systems," Automatica, vol. 94, pp. 236-248, Aug. 2018.

[5] M. F. Hamza, H. J. Yap, I. A. Choudhury, A. I. Isa, A. Y. Zimit, and T. Kumbasar, "Current development on using Rotary Inverted Pendulum as a benchmark for testing linear and nonlinear control algorithms," Mechanical Systems and Signal Processing, vol. 116, pp. 347-369, Feb. 2019.

[6] J. Huang, T. Zhang, Y. Fan, and J. Q. Sun, "Control of Rotary Inverted Pendulum Using Model-Free Backstepping Technique," IEEE Access, vol. 7, pp. 96965-96973, 2019.

[7] P. Dwivedi, S. Pandey, and A. S. Junghare, "Stabilization of unstable equilibrium point of rotary inverted pendulum using fractional controller," Journal of the Franklin Institute, vol. 354, no. 17, pp. 7732-7766, Nov. 2017.

[8] X. Chen, R. Yu, K. Huang, S. Zhen, H. Sun, and K. Shao, "Linear motor driven double inverted pendulum: A novel mechanical design as a testbed for control algorithms," Simulation Modelling Practice and Theory, vol. 81, pp. 31-50, Feb. 2018.

[9] H. Gao, X. Li, C. Gao, and J. Wu, "Neural network supervision control strategy for inverted pendulum tracking control," Discrete Dynamics in Nature and Society, vol. 2021, 2021.

[10] A. De Carvalho, J. F. Justo, B. A. Angelico, A. M. De Oliveira, and J. I. Da Silva Filho, "Rotary Inverted Pendulum Identification for Control by Paraconsistent Neural Network," IEEE Access, vol. 9, pp. 74155$74167,2021$. 
[11] A. Çakan, F. M. Botsali, and M. Tinkir, "PID control of inverted pendulum using adams and matlab co-simulation," ACM International Conference Proceeding Series, pp. 136-139, Dec. 2016.

[12] M. Waszak and R. Langowski, "An Automatic Self-Tuning Control System Design for an Inverted Pendulum," IEEE Access, vol. 8, pp. 26726-26738, 2020.

[13] Y. Silik and U. Yaman, "Control of Rotary Inverted Pendulum by Using On-Off Type of Cold Gas Thrusters," Actuators 2020, Vol. 9, Page 95, vol. 9, no. 4, p. 95, Sep. 2020.

[14] M. Magdy, A. El Marhomy, and M. A. Attia, "Modeling of inverted pendulum system with gravitational search algorithm optimized controller," Ain Shams Engineering Journal, vol. 10, no. 1, pp. 129149, Mar. 2019.

[15] A. S. Al-Araji, "An adaptive swing-up sliding mode controller design for a real inverted pendulum system based on Culture-Bees algorithm," European Journal of Control, vol. 45, pp. 45-56, 2019.

[16] T. Abut and S. Soyguder, "Real-time control and application with selftuning PID-type fuzzy adaptive controller of an inverted pendulum," Industrial Robot: the international journal of robotics research and application, vol. 46, no. 1, pp. 159-170, Apr. 2019.

[17] B. Kim and B. Park, "Robust Control for the Segway with Unknown Control Coefficient and Model Uncertainties," Sensors, vol. 16, no. 7, p. 1000, Jun. 2016.

[18] A. T. Azar, H. H. Ammar, M. H. Barakat, M. A. Saleh, and M. A. Abdelwahed, "Self-balancing Robot Modeling and Control Using Two Degree of Freedom PID Controller," Advances in Intelligent Systems and Computing, vol. 845, pp. 64-76, Sep. 2018.

[19] I. Gandarilla, V. Santibañez, and J. Sandoval, "Control of a selfbalancing robot with two degrees of freedom via IDA-PBC," ISA Transactions, vol. 88, pp. 102-112, May 2019.

[20] J.-H. Park and B.-K. Cho, "Development of a self-balancing robot with a control moment gyroscope," International Journal of Advanced Robotic Systems, vol. 15, no. 2, Apr. 2018.

[21] I. Rifajar and A. Fadlil, "The Path Direction Control System for Lanange Jagad Dance Robot Using the MPU6050 Gyroscope Sensor," International Journal of Robotics and Control Systems, vol. 1, no. 1, pp. 27-40, 2021.

[22] A. K. Kashyap, D. R. Parhi, and A. Pandey, "Analysis of Hybrid Technique for Motion Planning of Humanoid NAO," International Journal of Robotics and Control Systems, vol. 1, no. 1, pp. 75-83, 2021.

[23] Z. Ben Hazem, M. J. Fotuhi, and Z. Bingül, "Development of a FuzzyLQR and Fuzzy-LQG stability control for a double link rotary inverted pendulum," Journal of the Franklin Institute, vol. 357, no. 15, pp. 10529-10556, Oct. 2020.

[24] A. Jain, A. Sharma, V. Jately, B. Azzopardi, and S. Choudhury, "RealTime Swing-Up Control of Non-Linear Inverted Pendulum Using Lyapunov Based Optimized Fuzzy Logic Control," IEEE Access, vol. 9, pp. 50715-50726, 2021.

[25] I. Siradjuddin et al., "Stabilising a cart inverted pendulum with an augmented PID control scheme," MATEC Web of Conferences, vol. 197, p. 11013 , Sep. 2018.

[26] E. S. Varghese, A. K. Vincent, and V. Bagyaveereswaran, "Optimal control of inverted pendulum system using PID controller, LQR and MPC," IOP Conference Series: Materials Science and Engineering, vol. 263, no. 5, p. 052007, Nov. 2017.

[27] J. J. Wang, "Simulation studies of inverted pendulum based on PID controllers," Simulation Modelling Practice and Theory, vol. 19, no. 1, pp. 440-449, Jan. 2011.

[28] R. Shalaby, M. El-Hossainy, and B. Abo-Zalam, "Fractional order modeling and control for under-actuated inverted pendulum," Communications in Nonlinear Science and Numerical Simulation, vol. 74, pp. 97-121, Jul. 2019.

[29] M. Fauziyah, Z. Amalia, I. Siradjuddin, D. Dewatama, R. P. Wicaksono, and E. Yudaningtyas, "Linear quadratic regulator and pole placement for stabilizing a cart inverted pendulum system," Bulletin of Electrical Engineering and Informatics, vol. 9, no. 3, pp. 914-923, Jun. 2020.

[30] N. M. Tahir, M. Muhammad, M. Idi, S. Buyamin, L. Maijama'a, and S. M. Yarima, "Comparative analysis of observer-based LQR and LMI controllers of an inverted pendulum," Bulletin of Electrical Engineering and Informatics, vol. 9, no. 6, pp. 2244-2252, Dec. 2020.
[31] E. Susanto, A. Surya Wibowo, and E. Ghiffary Rachman, "Fuzzy Swing Up Control and Optimal State Feedback Stabilization for SelfErecting Inverted Pendulum," IEEE Access, vol. 8, pp. 6496-6504, 2020.

[32] Ü. Önen and A. Çakan, "Multibody Modeling and Balance Control of a Reaction Wheel Inverted Pendulum Using LQR Controller," International Journal of Robotics and Control Systems, vol. 1, no. 1, pp. 84-89, 2021.

[33] O. Saleem and K. Mahmood-Ul-Hasan, "Indirect Adaptive StateFeedback Control of Rotary Inverted Pendulum Using Self-Mutating Hyperbolic-Functions for Online Cost Variation," IEEE Access, vol. 8, pp. 91236-91247, 2020.

[34] M. Rabah, A. Rohan, and S.-H. Kim, "Comparison of Position Control of a Gyroscopic Inverted Pendulum Using PID, Fuzzy Logic and Fuzzy PID controllers," International Journal of Fuzzy Logic and Intelligent Systems, vol. 18, no. 2, pp. 103-110, Jun. 2018.

[35] A. I. Roose, S. Yahya, and H. Al-Rizzo, "Fuzzy-logic control of an inverted pendulum on a cart," Computers \& Electrical Engineering, vol. 61, pp. 31-47, Jul. 2017.

[36] A. Chmielewski, R. Gumiński, P. Maciąg, and J. Mączak, "The Use of Fuzzy Logic in the Control of an Inverted Pendulum," Springer Proceedings in Mathematics and Statistics, vol. 182, pp. 71-82, 2016.

[37] A. Bounemeur and M. Chemachema, "Adaptive Fuzzy Fault-Tolerant Control for a Class of Nonlinear Systems with Actuator Faults: Application to an Inverted Pendulum," International Journal of Robotics and Control Systems, vol. 1, no. 2, pp. 102-115, 2021.

[38] X. Xia, J. Xia, M. Gang, Q. Zhang, J. Wang, and J. Wang, "Discrete Dynamics-Based Parameter Analysis and Optimization of Fuzzy Controller for Inverted Pendulum Systems Based on Chaos Algorithm," Discrete Dynamics in Nature and Society, vol. 2020, 2020.

[39] A. K. Patra, S. S. Biswal, and P. K. Rout, "Backstepping Linear Quadratic Gaussian Controller Design for Balancing an Inverted Pendulum," IETE Journal of Research, 2019.

[40] M. S. Mahmoud, A. Alameer, and M. M. Hamdan, "An Adaptive Sliding Mode Control for Single Machine Infinite Bus System under Unknown Uncertainties," International Journal of Robotics and Control Systems, vol. 1, no. 3, pp. 226-243, 2021.

[41] S. Irfan, A. Mehmood, M. T. Razzaq, and J. Iqbal, "Advanced sliding mode control techniques for Inverted Pendulum: Modelling and simulation," Engineering Science and Technology, an International Journal, vol. 21, no. 4, pp. 753-759, Aug. 2018.

[42] I. Jmel, H. Dimassi, S. Hadj-Said, and F. M'Sahli, “An adaptive sliding mode observer for inverted pendulum under mass variation and disturbances with experimental validation," ISA Transactions, vol. 102, pp. 264-279, Jul. 2020.

[43] V. Petrov, "Nonlinear backstepping tracking control of DC motor driven inverted pendulum," IOP Conference Series: Materials Science and Engineering, vol. 878, no. 1, p. 012002, Jun. 2020.

[44] R. Uswarman, S. Istiqphara, and D. H. Tri Nugroho, "Sliding Mode Control with Gain Scheduled for Magnetic Levitation System," Jurnal Ilmiah Teknik Elektro Komputer dan Informatika, vol. 5, no. 1, pp. 3643, 2019.

[45] R. Uswarman, S. Istiqphara, R. A. Yunmar, and A. Z. Rakhman, "Robust Control of a Quadcopter Flying Via Sliding Mode," Journal of Science and Application Technology, vol. 2, no. 1, pp. 135-143, Jun. 2019.

[46] M. S. Mahmoud and A. H. AlRamadhan, "Optimizing the Parameters of Sliding Mode Controllers for Stepper Motor through Simulink Response Optimizer Application," International Journal of Robotics and Control Systems, vol. 1, no. 2, pp. 209-225, 2021.

[47] A. Chalanga, M. Patil, B. Bandyopadhyay, and H. Arya, "Output regulation using new sliding surface with an implementation on inverted pendulum system," European Journal of Control, vol. 45, pp. 85-91, Jan. 2019.

[48] S. Hadipour Lakmesari, M. J. Mahmoodabadi, and M. Yousef Ibrahim, "Fuzzy logic and gradient descent-based optimal adaptive robust controller with inverted pendulum verification," Chaos, Solitons and Fractals, vol. 151, p. 111257, 2021.

[49] S. K. Valluru and M. Singh, "Stabilization of nonlinear inverted pendulum system using MOGA and APSO tuned nonlinear PID controller," Cogent Engineering, vol. 4, no. 1, Jul. 2017.

[50] J. Liu, Sliding mode control using MATLAB. Academic Press, 2017. 